\title{
Autobiographical Narratives in Williams Syndrome: Structural, Process and Content Dimensions
}

\author{
Óscar F. Gonçalves • Ana P. Pinheiro • \\ Adriana Sampaio • Nuno Sousa • \\ Montse Férnandez • Margarida Henriques
}

Published online: 3 February 2011

(C) Springer Science+Business Media, LLC 2011

\begin{abstract}
Williams syndrome (WS) is a neurodevelopmental disorder, with an intriguing cognitive phenotype. Previous studies found support for an atypical profile of fictional narrative production in WS (Gonçalves et al. The British Journal of Developmental Disabilities, 56(111), 89-109, 2010). This study aimed at testing if the same profile is observed when individuals with WS tell autobiographical narratives. Using a new scoring system, structural (coherence), process (complexity) and content (multiplicity) aspects of autobiographical narrative production were analyzed in WS. Results suggest that individuals with WS produce autobiographical narratives that are significantly less coherent and complex than typically developing controls, although similar to controls in terms of content diversity. These findings point out to deficits in autobiographical narrative production in WS, suggesting the relative preservation of the social dimension of narrative production. These results also support the hypothesis that fictional and autobiographical narrative production may rely on different neurocognitive mechanisms.
\end{abstract}

Keywords Williams syndrome - Narrative - Autobiographical memory - Structure · Process $\cdot$ Content $\cdot$ Neurodevelopment

Narrating personal events is probably the most frequent event in social interactions (Fivush and Nelson 2004). This process involves different cognitive functions (e.g., episodic memory, emotion, attention, executive functions, language and semantic

Ó. F. Gonçalves $(\bowtie) \cdot A$. P. Pinheiro • A. Sampaio • M. Férnandez

Neuropsychophysiology Lab, CIPsi, School of Psychology, University of Minho, Campus de Gualtar,

4710-057 Braga, Portugal

e-mail: goncalves@psi.uminho.pt

N. Sousa

Life and Health Sciences Research Institute, University of Minho, Braga, Portugal

M. Henriques

Faculty of Psychology and Education Sciences, University of Porto, Porto, Portugal 
processes, as well as visual imagery) (Berntsen and Thomsen 2005; Conway 2003; Greenberg and Rubin 2003; Svoboda et al. 2006), it is organized within a narrative structure (Radvansky et al. 2005) and shared in a social context (Brown 1990; Bruner 1991; Engel 1995; Fivush and Nelson 2004; Linde 1993). Additionally, a remarkable similarity seems to exist between the way we organize personal and fictional narratives (Anderson and Conway 1993; Radvansky et al. 2005).

Developmental studies show that cognitive development is correlated with the ability to construct narratives and that both are associated with neurological development (Bauer et al. 2002). In fact, early in development, children develop the ability to represent their experience in a narrative way (Eisenberg 1985; Sachs 1983; Sutton-Smith 1986). As suggested by Fivush (1998), narrative promotes development of more coherent and subjective memories. Memories that are more coherently organized are also more easily accessed. However, little is known about the ability to develop autobiographical narratives in neurodevelopmental disorders, in which the brain is developing atypically since the beginning.

Williams syndrome (WS) is a genetic neurodevelopmental disorder caused by a submicroscopic deletion of approximately $1.6 \mathrm{Mb}$ including 24-28 genes on the long arm of chromosome 7 (7q11.23) (Korenberg et al. 2000). It is characterized by an unusual cognitive phenotype, in which an apparent preservation of narrative production and language coexists with profound intellectual deficits, specially visual-spatial and executive functioning impairments (Bellugi et al. 1997; Bellugi and St. George 2001; Mervis et al. 1999; see Martens et al. 2008 for a review; Semel and Rosner 2003).

Interestingly, most of the initial interest of WS research was fostered by apparent dissociative pattern of neurodevelopment (Bellugi et al. 1990), with the proposal of preserved cognitive "modules" namely language processing. In fact, it seems that, at least, the expressive language of individuals with WS is remarkably preserved, in contrast with other genetic syndromes characterized by mental retardation (e.g., Down syndrome). However, a detailed investigation of language subcomponents has revealed existence of several atypicalities, namely in terms of syntax, morphology, lexical-semantic processing, and pragmatics, in spite of a relatively good performance in receptive vocabulary tests (Brock 2002; Jarrold et al. 2000; Karmiloff-Smith et al. 1997; 1998, Karmiloff-Smith et al. 2002; Laws and Bishop 2004; Stojanovik et al. 2001; Vicari et al. 1996). These findings are corroborated by electrophysiological and neuroimaging studies, showing abnormalities in language processing in WS, such as an abnormal morphology of event-related potentials within the first $600 \mathrm{msec}$ to speech stimuli (e.g., Neville et al. 1989, 1994; Pinheiro et al. 2010) and the absence of patterns of normal asymmetry of core cortical areas for language processing (e.g., Superior Temporal Gyrus) in individuals with WS (Sampaio et al. 2008).

Previous studies have explored the narrative abilities of individuals with WS (Gonçalves et al. 2004, 2010; Heinze et al. 2007; Jones et al. 2000; Losh et al. 2000; Reilly et al. 2004). For example, Reilly et al. (2004) found significant deficits on cognitive measures of structural and thematic narrative dimensions (e.g., use of cognitive inferences) by individuals with WS, suggesting a failure to integrate the different elements of narrative. However, some strength was found for the use of evaluative devices (i.e., social engagement) in WS narratives, when compared with other disorders (specific language impairment). More recently, Gonçalves et al. 
(2010) studied the structure, process, and content of fictional narrative production in participants with WS, taking typical development (age-matched controls) as a comparison. Overall, their findings suggest that participants with WS not only show significant lower levels of narrative coherence, complexity and diversity but also that their narrative profile seems to privilege the diversity of narrative content at the expense of narrative coherence.

In sum, studies on WS fictional narrative production suggest a dissociation between the expressive and the metacognitive dimensions of narrative. In spite of the relative proficiency shown in the use of some linguistic forms (e.g., morphosyntactic abilities) and the abundant use of social engagement tools (evaluative devices), existing studies are consensual in showing deficits in the more cognitive dimensions of the narrative (e.g., reference to the motivations, inferences and goals of story's characters, linked to theory-of-mind ability; integration of the different episodic and thematic elements of the story).

Taking into account the existing evidence, this study aimed at accomplishing a double goal: (1) characterizing the narrative profile of WS individuals in the context of an autobiographical narrative task; (2) testing if the same profile of narrative production is observed in all narrative tasks (fictional and autobiographical) or if it differs when related with the expression of autobiographical and personally significant events.

By using a new scoring system, structural (coherence), process (complexity) and content (multiplicity) aspects of autobiographical narrative production in WS were compared with those of a write typically developing group. Based on the existing evidence, we expected a lower performance of individuals with WS in structure and process dimensions, and a relative preservation of autobiographical narrative content, associated with strengths in social-emotional aspects of narrative production.

\section{Method}

\section{Participants}

A group of thirteen participants (4 female and 9 male), diagnosed with Williams Syndrome, with age range between 11 and 29 years, was compared with a typically developing group, individually matched for chronological age $(M=19.33, S D=5.80)$, gender, and socio-economic level $(M=3.77, S D=0.89)$. No significant group differences were observed with respect to socio-demographic characteristics, including age $(t(18)=-.153, p>.05)$ and socio-economic status - Graffar Index $(Z=-.932, p>.05)$ (see Table 1).

Participants with WS were recruited at a Genetic Medical Institute in Oporto (Portugal) and at the Genomic Foundation in Galicia (Spain). WS diagnoses were made by fluorescent in situ hybridization (FISH) confirmation of elastin gene deletion (Korenberg et al. 2000). Exclusion criteria included presence of severe sensorial or speech disorder, as well as comorbidity with severe psychopathology not associated with the syndrome. Controls were typically developing individuals without evidence of psychiatric, neurological disorder, or cognitive impairment. Participants and their guardians gave written informed consent for their 
Table 1 Socio-demographic characteristics of participants

\begin{tabular}{|c|c|c|c|c|c|c|c|c|}
\hline & & \multicolumn{3}{|c|}{ Williams Syndrome $(N=13)$} & & \multicolumn{3}{|c|}{ Typically Developing Group $(N=13)$} \\
\hline & & Range & M & SD & & Range & M & SD \\
\hline \multicolumn{9}{|l|}{ Gender } \\
\hline Female & 9 & - & - & - & 9 & - & - & - \\
\hline Male & 4 & - & - & - & 4 & - & - & - \\
\hline Age & & $11-29$ & 16.77 & 6.51 & & $11-29$ & 16.62 & 6.57 \\
\hline Education & & $4-12$ & 6.92 & 3.00 & & $4-12$ & 8.67 & 2.87 \\
\hline Socio-Economical Level ${ }^{\mathrm{a}}$ & & $5-3$ & 3.85 & 0.77 & & $5-2$ & 3.77 & 0.89 \\
\hline
\end{tabular}

${ }^{\text {a }}$ Graffar Scale (1-high level; 5-low level)

participation in the study via consent forms, after a detailed description of the study.

\section{Instruments}

To assess general cognitive functioning (Full Scale IQ), participants 8-16 years of age were administered the Wechsler Intelligence Scale for Children-Third Edition (WISC-III) (Wechsler 1991), while subjects over 16 years old were administered the Wechsler Adult Intelligence Scale - Third Edition (WAIS-III) (Wechsler 1997).

In order to analyze autobiographical narrative production, an autobiographical elicitation task was used. Participants were asked to answer an open-ended question about any personal significant life event ("Tell me a very important event in your life"). Interviewers were trained to react only with minimal encouragement for further elaboration (e.g., "Can you tell me anything else?"). All the narratives obtained were videotaped, transcribed and analyzed in terms of its structure, process and content, based on specific coding systems developed by Gonçalves et al. (2002). Each system assesses four subdimensions of a specific narrative aspect- structure, process and content - in a 5-point Likert scale. Besides the score for each individual subdimension, a global score can be obtained for the three narrative major dimensions (content, process or structure) by summing each subdimension scores corrected for the deviations. Acceptable levels of inter-rater reliability $(86 \%-96 \%)$ and internal consistency (alpha values from .66 to .93) have been described for these coding systems (Gonçalves et al. 2002). Below, a brief characterization of each system is provided.

(a) The System for the Assessment of the Structural Coherence of Narrative (Gonçalves and Henriques 2000a), based on the narrative structure models of Labov and Waletzky (1967) and Baeger and McAdams (1999), aims at evaluating narrative coherence using a coding system composed by four subdimensions: orientation, structural sequence, evaluative commitment and integration (Table 2). 
Table 2 Subdimensions of narrative structure

I. Structural coherence

a) Orientation Does the narrative make reference to: What is the context of the narrative?

- characters?

- the social / spatial / temporal / personal context where behaviors take place?

- past relevant events that have contributed for the occurrence of current behaviors?

- relevant events that have occurred after the central event?

b) Structural

Does the narrative make reference to:

And then, what happened?

coherence

- an initial event?

- an internal response to the event?

- an action?

- the associated consequences?

c) Evaluative

Does the narrative make reference to:

commitment

- the emotional states of the narrator?

- the extent of his commitment with the narrative?

d) Integration

Are the elements of narrative described in an integrated/coherent manner?

Does the logic of the story flow in a clear, coherent and articulated way?

(b) The System for the Assessment of Narrative Process Complexity (Gonçalves and Henriques 2000b) is based on the systems previously developed by Angus et al. (1999) for the analysis of narrative process in oral narratives, and it aims at assessing the level of complexity in the narrative process using four indexes: objectifying, emotional subjectifying, cognitive subjectifying, and metaphorizing (Table 3).

Table 3 Subdimensions of narrative process

II. Narrative process complexity

a) Objectifying Does the narrative make reference to:

- Sensorial elements related with the episode's description? In what extent?

b) Emotional Does the narrative make reference to: subjectifying

- Emotional states related with specific events? In what extent?

c) Cognitive Does the narrative make reference to:

subjectifying - Cognitions, ideas, thoughts and plans of the characters mentioned? In what extent?

d) Metaphoryzing Does the narrative make reference to:

- The meanings constructed by the narrator, in order to make sense of the episodes described?
What are the sensory experiences of the characters?

What are the emotional experiences of the characters?

What are the cognitive experiences of the characters?

How does the narrator make sense of the events described? 
(c) Finally, the System for the Assessment of Narrative Content Diversity (Gonçalves and Henriques 2000c) aims at assessing the diversity of narratives in terms of themes, events, settings, and characters (Table 4).

\section{Procedure}

After data collection on the sociodemographic characteristics, diagnosis, clinical history, and general cognitive functioning of participants, the experimental procedure took place. All participants were asked to complete the autobiographical elicitation task, answering to an open-ended question about any personal significant life event. Participants' narratives were videotaped and further transcribed. The narratives obtained were then analyzed according to the structure, process and content systems described above.

Three psychologists, blind to the study hypotheses, were involved in the process of collecting socio-demographic data, conducting global cognitive assessment and administrating the narrative induction task. Six additional psychologists, equally blind to participants' diagnosis, coded the narratives (two judges for each coding system). The observers were trained (at least $60 \mathrm{~h}$ ) in narratives' coding, based on the Narrative Analysis System (Gonçalves et al. 2002). Inter-rater agreement was calculated for all the narratives using the Within Class Correlation Coefficient (Everitt and Hay 1992), and all discrepancies were solved by consensus. Inter-rater agreement before consensus was above $80 \%$ for all the subdimensions analyzed.

Groups were compared for cognitive and narrative data. Between-group comparisons for cognitive data were performed using independent samples t-tests. In order to get a comprehensive view of group differences in the autobiographical narrative task, independent samples t-tests were computed first for each narrative dimension (structure, process, and content), and second for each narrative subdimension.

\section{Results}

Cognitive Measures

Mean distribution of FSIQ in WS was found to be within the moderate mental retardation interval, with equally low scores in verbal and performance IQ. As

Table 4 Subdimensions of narrative content

III. Narrative content diversity

\begin{tabular}{|c|c|c|}
\hline a) Themes & - How many themes are introduced in the narrative? & $\begin{array}{l}\text { What are the thematic contexts } \\
\text { introduced in the narrative? }\end{array}$ \\
\hline b) Events & - How many action sequences are described? & And then, what happened? \\
\hline c) Scenarios & $\begin{array}{l}\text { - Does the narrative make reference to the } \\
\text { environment that surrounds the events described? }\end{array}$ & $\begin{array}{l}\text { What is the context where action } \\
\text { takes place? }\end{array}$ \\
\hline d) Characters & $\begin{array}{l}\text { - How many (real or imagined) characters are } \\
\text { introduced in the narrative? }\end{array}$ & $\begin{array}{l}\text { Who are the agents of the actions } \\
\text { described? }\end{array}$ \\
\hline
\end{tabular}


expected, typically developing participants showed significantly higher levels of General IQ (FSIQ), as well as of Verbal and Performance IQ (see Table 5).

\section{Narrative Measures}

\section{Global Narrative Measures}

Overall, WS autobiographical narratives (see Appendix for an example) were significantly lower in quality, when taking into account the mean scores for structure and process dimensions. Findings suggest a significant lower structural coherence, and lower process complexity in WS individuals relative to typically developing controls. However, no group differences were observed for content diversity (see Table 6 and Fig. 1).

Below, significant findings for each narrative subdimension are described.

\section{Narrative Structural Coherence}

Group comparisons did not show significant differences for orientation, structural coherence, and evaluative commitment structural dimensions. However, individuals with WS were found to present significantly lower scores of narrative integration (see Table 7).

\section{Narrative Process Complexity}

Scores for narrative process were also significantly lower in the WS group relative to typically developing controls (see Table 8).

Overall, WS narratives were found to be very poor in terms of emotional (emotional subjectifying), cognitive (cognitive subjectifying) and meaning diversity (metaphorizing). Even though the scores for typically developing controls were also poor in all dimensions with the exception of objectifying, they were still significantly higher than those observed in participants with WS.

\section{Narrative Content Diversity}

No significant group differences were found for the global scores of narrative content (see Table 9).

Table 5 Cognitive profile of patients with WS and controls

\begin{tabular}{|c|c|c|c|c|c|c|c|c|c|c|}
\hline & \multicolumn{4}{|c|}{ Williams Syndrome $(N=13)$} & \multicolumn{4}{|c|}{ Typically Developing Group $(N=13)$} & \multicolumn{2}{|c|}{ Statistical test } \\
\hline & Min. & Max. & $M$ & $S D$ & Min. & Max. & $M$ & $S D$ & $t$ & $p$ \\
\hline Full Scale IQ & 40 & 69 & 47.31 & 7.05 & 84 & 129 & 95.38 & 15.23 & 9.920 & $<.001$ \\
\hline Verbal IQ & 46 & 80 & 53.15 & 8.77 & 82 & 130 & 96.38 & 14.47 & 8.850 & $<.001$ \\
\hline Performance IQ & 46 & 61 & 50.46 & 4.86 & 84 & 119 & 96.23 & 14.55 & 10.338 & $<.001$ \\
\hline
\end{tabular}


Table 6 Global scores for autobiographical narrative structure, process and content in participants with WS and controls

\begin{tabular}{|c|c|c|c|c|c|c|}
\hline \multirow[t]{2}{*}{ Narrative dimensions } & \multicolumn{2}{|c|}{ Williams Syndrome $(N=13)$} & \multicolumn{2}{|c|}{ Typically Developing Group $(N=13)$} & \multicolumn{2}{|c|}{ Statistical test } \\
\hline & $M$ & $S D$ & $M$ & $S D$ & $t$ & $p$ \\
\hline Structure & 19.08 & 16.63 & 34.50 & 19.65 & 2.124 & $<.05$ \\
\hline Process & 16.83 & 8.67 & 39.17 & 21.70 & 3.311 & $<.01$ \\
\hline Content & 43.50 & 19.39 & 32.83 & 13.20 & -1.575 & n.sig. \\
\hline
\end{tabular}

n. sig. indicates non significant

However, when looking at the different subcomponents of this dimension (see Table 9), individuals with WS revealed significantly higher scores for events diversity relative to typically developing controls. No significant differences were found for the other subcomponents.

\section{Discussion}

This study aimed at describing structure, content, and diversity of autobiographical narratives of individuals with WS, taking typical development as a reference, by using a new scoring system.

Results showed deficits in WS autobiographical narrative production, in terms of structural coherence (particularly narrative integration) as well as process complexity. However, the WS group was no different from a typically developing group in the global scores of content diversity. When considering each narrative subdimension, WS participants presented significantly lower scores in integration, as well as in objectifying, cognitive subjectifying and metaphoryzing. In contrast, higher scores in terms of events diversity were found in the WS group.

In particular, for narrative structure, integration seems to be the only variable significantly affected in WS. In other words, structural difficulties exhibited by

Fig. 1 Comparison between WS and control groups for the three central narrative dimensions

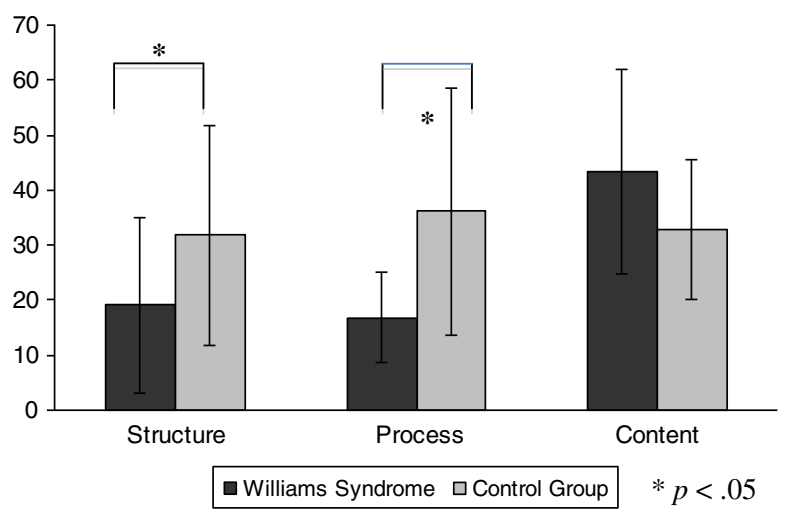


Table 7 Scores for the subdimensions of autobiographical narrative structure and coherence in participants with WS and controls

\begin{tabular}{|c|c|c|c|c|c|c|}
\hline \multirow[t]{2}{*}{ Structure Parameters } & \multicolumn{2}{|c|}{$\begin{array}{l}\text { Williams Syndrome } \\
(N=13)\end{array}$} & \multicolumn{2}{|c|}{$\begin{array}{l}\text { Typically Developing Group } \\
(N=13)\end{array}$} & \multicolumn{2}{|c|}{ Statistical test } \\
\hline & $M$ & $S D$ & $M$ & $S D$ & $t$ & $p$ \\
\hline Orientation & 1.92 & 0.86 & 2.58 & 1.00 & 2.085 & n.sig. \\
\hline Structural Sequence & 1.85 & 0.99 & 2.50 & 1.24 & 1.342 & n.sig. \\
\hline Evaluative Commitment & 2.38 & 1.56 & 3.25 & 1.06 & 3.664 & n.sig. \\
\hline Integration & 1.54 & 0.78 & 12.42 & 1.08 & 3.336 & n.sig. \\
\hline
\end{tabular}

n. sig. indicates non significant

participants with WS in autobiographical narratives seem to be due to problems with narrative integration in the context of relatively spared orientation, structural coherence and evaluative commitment abilities. These findings contrast with previous findings on WS fictional narratives that showed deficits in all subdimensions of narrative structure (Gonçalves et al. 2010). The discrepancy between the two types of narrative production suggests that the structural dimensions of autobiographical narratives may be less affected than fictional narratives in WS. This may be due to higher executive functioning demands in the fictional narrative task (Kleinknecht and Beike 2004; Tannock et al. 1993), an ability that is often affected in WS (Bellugi et al. 1990; Bellugi et al. 2000; Bellugi et al. 1994; Meyer-Lindenberg et al. 2005; Tager-Flusberg et al. 1997). In addition, previous studies showed that, in narrating personal events, individuals with WS tend to tell repeatedly a stereotyped narrative across situations and interlocutors (Bellugi et al. 1997; Doyle et al. 2004). So it is plausible that, when retelling the same autobiographical events over and over again, individuals with WS consolidate the structure of those narratives. This may explain why they have better results of structural coherence in autobiographical narratives, in spite of the low level of narrative integration. In fact, these findings seem to be consistent with developmental studies showing that the process of engaging in past event conversations helps to enrich narratives, since children are more able to add more and more unique details to their

Table 8 Scores for the subdimensions of autobiographical narrative process and complexity in participants with WS and controls

\begin{tabular}{|c|c|c|c|c|c|c|}
\hline \multirow[t]{2}{*}{ Process Parameters } & \multicolumn{2}{|c|}{$\begin{array}{l}\text { Williams Syndrome } \\
(N=13)\end{array}$} & \multicolumn{2}{|c|}{$\begin{array}{l}\text { Typically Developing Group } \\
(N=13)\end{array}$} & \multicolumn{2}{|c|}{ Statistical test } \\
\hline & $M$ & $S D$ & $M$ & $S D$ & $t$ & $p$ \\
\hline Objectifying & 2.33 & 0.78 & 3.83 & 2.37 & 2.085 & $<.05$ \\
\hline Emotional Subjectifying & 1.92 & 0.51 & 2.17 & 0.39 & 1.342 & n.sig \\
\hline Cognitive Subjectifying & 1.58 & 0.67 & 2.58 & 0.67 & 3.664 & $<.01$ \\
\hline Metaphorizing & 1.17 & 0.39 & 2.25 & 1.06 & 3.336 & $<.01$ \\
\hline
\end{tabular}

n. sig. indicates non significant 
Table 9 Scores for the subdimensions of autobiographical narrative content and diversity in participants with WS and controls

\begin{tabular}{|c|c|c|c|c|c|c|}
\hline \multirow[t]{2}{*}{ Content Parameters } & \multicolumn{2}{|c|}{ Williams Syndrome $(N=13)$} & \multicolumn{2}{|c|}{ Typically Developing Group $(N=13)$} & \multicolumn{2}{|c|}{ Statistical test } \\
\hline & $M$ & $S D$ & $M$ & $S D$ & $t$ & $p$ \\
\hline Characters & 3.17 & 1.40 & 3.42 & 1.16 & 0.475 & N.S. ${ }^{\text {a }}$ \\
\hline Scenarios & 3.33 & 1.50 & 2.50 & 1.17 & -1.520 & N.S. ${ }^{a}$ \\
\hline Events & 3.67 & 1.15 & 2.42 & 0.90 & -2.957 & $<.01$ \\
\hline Themes & 2.42 & 1.08 & 2.00 & 0.43 & -1.239 & n.sig. \\
\hline
\end{tabular}

n. sig. indicates non significant

narratives, until these personal stories become more integrated and organized around a central theme (e.g., Kleinknecht and Beike 2004). These studies also show that, as children organize their personal experiences in a narrative format, they are better able to successfully encode, store and retrieve information related with these personal event memories (Kleinknecht and Beike 2004).

A different pattern was found in terms of process complexity, in which significant deficits were observed, as in a previous fictional narrative task (see Gonçalves et al. 2010). Groups differed in all subdimensions of narrative process, with the exception of emotional subjectifying. This finding contrasts with a previous study on fictional narrative production in WS (Gonçalves et al. 2010) but seems to be consistent with studies reporting a relative preservation of affective language in the narratives of participants with WS (Reilly et al. 1991). The nature of the narrative task (organizing fictional events vs. personal events within a narrative structure) may explain the discrepancy with previous studies.

Finally, a finding worth noting is the absence of significant differences between WS and typically developing controls in terms of the diversity of narrative content. Even though previous findings pointed out that WS fictional narratives seem to rely on content devices (e.g., diversity of characters) (Gonçalves et al. 2010), it is in the context of autobiographical narratives that the preservation of content diversity is more evident. However, it is worth noting that both groups presented low scores for themes production. It is possible that these findings were biased by the structured nature of the narrative induction task, which can favour the reduced expression of thematic diversity, limiting the ability to discriminate the groups under comparison.

In sum, our study suggests that individuals with WS rely their autobiographical narrative production on the diversity of contents that are shared with the interlocutor. However, those autobiographical narratives tend to lack both integration and complexity. Characteristics of WS autobiographical narrative profile seem to be consistent with the hipersociable features often described in this syndrome (Bellugi et al. 1999; Jones et al. 2000; Klein-Tasman and Mervis 2003). In addition, the current findings also seem to be consistent with the peculiarities of the language profile in WS reported in previous studies as the high levels of linguistic production associated with a verborreic style or "cocktail party" speech (Bellugi et al. 1992), the use of "audience hookers" (Bellugi et al. 2007; Jarvinen-Pasley et al. 
2008; Jones et al. 2000), as well as the stereotypical nature of conversation, coexisting with pragmatic deficits (e.g., initiation of conversation; reciprocal communication) (Laws and Bishop 2004).

Autobiographical remembering is a social enterprise that helps to create or strengthen social relationships (Kleinknecht and Beike 2004). In other words, the social nature of personal storytelling may explain the preservation of some aspects of autobiographical narrative production in WS social phenotype. In contrast, fictional narrative production may depend more upon cognitive domains, namely theory of mind abilities, which are affected in WS (e.g., Karmiloff-Smith et al. 1995; Sullivan and Tager-Flusberg 1999; Tager-Flusberg et al. 1998; Tager-Flusberg and Sullivan 2000). Indeed, Kleinknecht and Beike (2004) suggest that theory of mind seems to be related with the breadth and content of fictional narratives and not necessarily with personal event accounts. Thus, while fictional narratives seem to be more associated with cognitive domains, autobiographical narratives may be more dependent on social-emotional variables. Overall, cognitive deficits shown by participants with WS may explain the discrepancy between current data on autobiographical narratives and previous studies on fictional narratives.

The current findings thus provide, for the first time, data on the profile of autobiographical narrative production in WS. However, some limitations need to be pointed out, namely the broad age range of the participants and the small size of our samples. Future studies should address these limitations and include other control groups, namely a mental-age or language-related matched control group, to allow the differentiation between the aspects of narrative skills related to language delay and cognitive retardation in WS from those that are specific of its narrative profile.

In spite of these limitations, the current findings are expected to contribute to a better understanding of the autobiographical narrative profile in WS, suggesting that the retrieval of personal memories and their embedment in an integrated and coherent narrative is a complex neurocognitive process occurring atypically in a brain that is atypical since the beginning.

Acknowledgements This research was supported by the grants SFRH/BD/35882/2007 and PIC/IC/ 83290/2007from Fundação para a Ciência e Tecnologia (Portugal).

\section{References}

Anderson, S. J., \& Conway, M. A. (1993). Investigating the structure of autobiographical memories. Journal of Experimental Psychology, 19(5), 1178-1196.

Angus, L. E., Levitt, H., \& Hardtke, K. (1999). The narrative process coding system: Research applications and implications for psychotherapy practice. Journal of Clinical Psychology, 55, 1255-1270.

Baeger, D. R., \& McAdams, D. P. (1999). Life story coherence and its relation to psychological wellbeing. Narrative Inquiry, 9(1), 69-96.

Bauer, P. J., Burch, M. M., \& Kleinknecht, E. E. (2002). Developments in early recall memory: normative trends and individual differences. Advances in Child Development and Behavior, 30, 103-152.

Bellugi, U., Adolphs, R., Cassady, C., \& Chiles, M. (1999). Towards the neural basis for hypersociability in a genetic syndrome. NeuroReport, 10, 1653-1657.

Bellugi, U., Bihrle, A., Jernigan, T., Trauner, D., \& Doherty, S. (1990). Neuropsychological, neurological, and neuroanatomical profile of Williams syndrome. American Journal of Medical Genetics. Supplement, 6, 115-125. 
Bellugi, U., Bihrle, A., Neville, H., Jernigan, T., \& Doherty, S. (1992). Language, cognition, and brain organization in a neurodevelopmental disorder. In M. Gunnar \& C. Nelson (Eds.), Developmental Behavioral neuroscience (pp. 201-232). Hillsdale: Erlbaum.

Bellugi, U., Järviven-Pasley, A., Doyle, T. F., Reilly, J., Reiss, A. S., \& Korenberg, J. R. (2007). Affect, social behavior, and the brain in Williams syndrome. Current Directions in Psychological Science, 16 (2), 99-104.

Bellugi, U., Lai, Z., \& Wang, P. (1997). Language, communication and neural systems in Williams Syndrome. Mental Retardation and Developmental Disabilities Research Reviews, 3, 334-342.

Bellugi, U., Lichtenberger, L., Jones, W., Lai, Z., \& George, M. S. (2000). The neurocognitive profile of Williams Syndrome: A complex pattern of strengths and weaknesses. Journal of Cognitive Neuroscience, 12, 7-29.

Bellugi, U., \& St. George, M. (2001). Journey from cognition to brain to gene. Cambridge: MIT Press.

Bellugi, U., Wang, P. P., \& Jernigan, T. L. (1994). Williams Syndrome: An unusual neuropsyhological profile. In S. Broman \& J. Grafman (Eds.), Atypical cognitive deficits in developmental disorders: Implications for brain function. Hillsdale: Lawrence Erlbaum Associates.

Berntsen, D., \& Thomsen, D. K. (2005). Personal memories for remote historical events: accuracy and clarity of flashbulb memories related to World War II. Journal of Experimental Psychology: General, 134(2), 242-257.

Brock, J. (2002). Language abilities in Williams syndrome: A critical review. Development and Psychopathology, 19, 97-127.

Brown, N. R. (1990). Organization of public events in long-term memory. Journal of Experimental Psychology: General, 119, 297-314.

Bruner, J. (1991). The Narrative Construction of Reality. Critical Inquiry, 18(1), 1-21.

Conway, M. A. (2003). Commentary: cognitive-affective mechanisms and processes in autobiographical memory. Memory, 11(2), 217-224.

Doyle, T. F., Bellugi, U., Korenberg, J. R., \& Graham, J. (2004). "Everybody in the world is my friend": Hypersociability in young children with Williams syndrome. American Journal of Medical Genetics, $124 A, 263-273$.

Eisenberg, A. R. (1985). Learning to describe past experiences in conversation. Discourse Processes, 8(2), $177-204$.

Engel, S. (1995). The stories children tell: Making sense of the narratives of childhood. San Francisco: Freeman.

Everitt, B., \& Hay, D. (1992). Measurement, observer bias and reliability. In B. Everitt \& D. Hay (Eds.), Talking about statistics: A psychologist's guide to design and analysis. London: Edward Arnold.

Fivush, R. (1998). The stories we tell: how language shapes autobiography. Applied Cognitive Psychology, $12,483-487$.

Fivush, R., \& Nelson, K. (2004). Culture and language in the emergence of autobiographical memory. Psychological Science, 15(9), 573-577.

Gonçalves, O. F. (1995). Cognitive narrative psychotherapy. In M. J. Mahoney (Ed.), Cognitive and constructive psychotherapies. New York: Springer.

Gonçalves, O. F., \& Henriques, M. R. (2000a). Manual de avaliação do conteúdo e diversidade narrativa (System for the Assessment of Narrative Content Diversity). Braga: Universidade do Minho.

Gonçalves, O. F., \& Henriques, M. (2000b). Manual de avaliação da estrutura e coerência narrativa (System for the Assessment of the Structural Coherence of Narrative). Braga: Universidade do Minho.

Gonçalves, O. F., \& Henriques, M. R. (2000c). Manual de avaliação do processo e complexidade narrativa (System for the Assessment of Narrative Process Complexity). Braga: Universidade do Minho.

Gonçalves, O. F., Henriques, M. R., Alves, A., \& Soares, L. (2002). Analyzing structure, process and content in narratives of patients diagnosed with agoraphobia. International Journal of Clinical and 398 Health Psychology, 2(3), 389-406.

Gonçalves, O. F., Pérez, A., Henriques, M., Prieto, M., Lima, M., Siebert, M., et al. (2004). Funcionamento cognitivo e produção narrativa no Síndrome de Williams: Congruência ou dissociação neurocognitiva? (Cognitive functioning and narrative production in Williams Syndrome: Congruence or neurocognitive dissociation). International Journal of Clinical and Health Psychology, 4(3), 623-638.

Gonçalves, O. F., Pinheiro, A. P., Sampaio, A., Sousa, N., Férnandez, M., \& Henriques, M. (2010). The narrative profile in Williams Syndrome: There is more to storytelling than just telling a story. The British Journal of Developmental Disabilities, 56(111), 89-109.

Greenberg, D. L., \& Rubin, D. C. (2003). The neuropsychology of autobiographical memory. Cortex, 39 (4-5), 687-728. 
Heinze, E. G., Prieto, M. F., Sampaio, A., \& Gonçalves, O. (2007). Valoración interlingüística de la producción verbal a partir de una tarea narrativa en el síndrome de Williams. Psicothema, 19(3), 428-434.

Jarrold, C., Hartley, S. J., Phillips, C., \& Baddeley, A. D. (2000). Word fluency in Williams Syndrome: Evidence for unusual semantic organisation? Cognitive Neuropsychiatry, 5(4), 293-319.

Jarvinen-Pasley, A., Bellugi, U., Reilly, J., Mills, D. L., Galaburda, A., Reiss, A. L., et al. (2008). Defining the social phenotype in Williams syndrome: a model for linking gene, the brain, and behavior. Developmental Psychopathology, 20(1), 1-35.

Jones, W., Bellugi, U., Lai, Z., Chiles, M., Reilly, J., Lincoln, A., et al. (2000). II. Hypersociability in Williams Syndrome. Journal of Cognitive Neuroscience, 12(Suppl 1), 30-46.

Karmiloff-Smith, A., Grant, J., Berthoud, I., Davies, M., Howlin, P., \& Udwin, O. (1997). Language and Williams syndrome: how intact is "intact"? Child Development, 68(2), 246-262.

Karmiloff-Smith, A., Klima, E., Bellugi, U., Grant, J., \& Baron-Cohen, S. (1995). Is There a Social Module? Language, Face Processing, and Theory of Mind in Individuals with Williams Syndrome. Journal of Cognitive Neuroscience, 7(2), 196-208.

Karmiloff-Smith, A., Scerif, G., \& Thomas, M. (2002). Different approaches to relating genotype to phenotype in developmental disorders. Developmental Psychobiology, 40(3), 311-322.

Karmiloff-Smith, A., Tyler, L. K., Voice, K., Sims, K., Udwin, O., Howlin, P., et al. (1998). Linguistic dissociations in Williams syndrome: evaluating receptive syntax in on-line and off-line tasks. Neuropsychologia, 36(4), 343-351.

Kleinknecht, E., \& Beike, D. R. (2004). How Knowing and Doing Inform an Autobiography: Relations Among Preschoolers' Theory of Mind, Narrative, and Event Memory Skills. Applied Cognitive Psychology, 18, 745-764.

Klein-Tasman, B. P., \& Mervis, C. B. (2003). Distinctive personality characteristics of 8-, 9-, and 10-yearolds with Williams syndrome. Developmental Neuropsychology, 23, 269-290.

Korenberg, J. R., Chen, X. N., Hirota, H., Lai, Z., Bellugi, U., Burian, D., et al. (2000). VI. Genome structure and cognitive map of Williams syndrome. Journal of Cognitive Neuroscience, 12(Suppl 1), 89-107.

Labov, W., \& Waletzky, J. (1967). Narrative analysis: Oral versions of personal experience. In J. Helm (Ed.), Essays on the verbal and visual arts: Proceedings of the 1996 Annual Spring Meeting of the American Ethnological Society. Seattle: University of Washington Press.

Laws, G., \& Bishop, D. (2004). Pragmatic language impairment and social deficits in Williams syndrome: a comparison with Down's syndrome and specific language impairment. International Journal of Language \& Communication Disorders, 39(1), 45-64.

Linde, C. (1993). Life stories: the creation of coherence. New York: Oxford University Press.

Losh, M., Bellugi, U., Reilly, J., \& Anderson, D. (2000). Narrative as a social engagement tool: The excessive use of evaluation in narratives from children with Williams Syndrome. Narrative Inquiry, $10(2), 265-290$.

Martens, M. A., Wilson, S. J., \& Reutens, D. C. (2008). Research Review: Williams syndrome: a critical review of the cognitive, behavioral, and neuroanatomical phenotype. Journal of Child Psychology and Psychiatry, 49(6), 576-608.

Mervis, C. B., Morris, C. A., Bertrand, J., \& Robinson, B. F. (1999). Williams Syndrome: Findings from an integrated program of research. In H. Tagen-Flusberg (Ed.), Neurodevelopmental Disorders. The MIT Press.

Meyer-Lindenberg, A., Hariri, A. R., Munoz, K. E., Mervis, C. B., Mattay, V. S., Morris, C. A., et al. (2005). Neural correlates of genetically abnormal social cognition in Williams syndrome. Nature Neuroscience, 8(8), 991-993.

Neville, H. J., Holcomb, P. J., \& Mills, D. M. (1989). Auditory sensory and language processing in Williams syndrome: An ERP study. Journal of Clinical and Experimental Neuropsychology, 11, 52.

Neville, H. J., Mills, D. L., \& Bellugi, U. (1994). Effects of altered auditory sensitivity and age of acquisition on the development of language-relevant neural systems: Preliminary studies of Williams Syndrome. In S. Broman \& J. Grafman (Eds.), Atypical cognitive deficits in developmental disorders: Implications for brain function (pp. 67-83). Hillsdale: Erlbaum.

Pinheiro, A. P., Galdo-Alvarez, S., Sampaio, A., Niznikiewicz, M., \& Goncalves, O. F. (2010). Electrophysiological correlates of semantic processing in Williams syndrome. Research in Developmental Disabilities, 31(6), 1412-1425.

Radvansky, G. A., Copeland, D. E., \& Zwaan, R. A. (2005). A novel study: investigating the structure of narrative and autobiographical memories. Memory, 13(8), 796-814. 
Reilly, J., Klima, E. S., \& Bellugi, U. (1991). Once more with feeling: Affect and language in atypical populations. Development and Psychopathology, 367-391.

Reilly, J., Losh, M., Bellugi, U., \& Wulfeck, B. (2004). "Frog, where are you?" Narratives in children with specific language impairment, early focal brain injury, and Williams syndrome. Brain and Language, $88,229-247$.

Sachs, J. (1983). Talking about the there and then: The emergence of displaced reference in parent-child discourse. In K. Nelson (Ed.), Children's Language (Vol. 4, pp. 1-28). Hillsdale: Erlbaum.

Sampaio, A., Sousa, N., Fernandez, M., Vasconcelos, C., Shenton, M. E., \& Goncalves, O. F. (2008). MRI assessment of superior temporal gyrus in Williams syndrome. Cognitive and Behavioral Neurology, 21(3), 150-156.

Semel, E., \& Rosner, S. R. (2003). Understanding Williams syndrome. Mahwah: Laurence Erlbaum.

Stojanovik, V., Perkins, M., \& Howard, S. (2001). Language and conversational abilities in Williams syndrome: how good is good? International Journal of Language \& Communication Disorders. Suppl, $36,234-239$.

Sullivan, K., \& Tager-Flusberg, H. (1999). Second-order belief attribution in Williams syndrome: intact or impaired? American Journal of Mental Retardation, 104(6), 523-532.

Sutton-Smith, B. (1986). Children's fiction making. In T. R. Sarbin (Ed.), Narrative Psychology. New York: Praeger.

Svoboda, E., McKinnon, M. C., \& Levine, B. (2006). The functional neuroanatomy of autobiographical memory: a meta-analysis. Neuropsychologia, 44(12), 2189-2208.

Tager-Flusberg, H., Boshart, J., \& Baron-Cohen, S. (1998). Reading the windows to the soul: evidence of domain-specific sparing in Williams syndrome. Journal of Cognitive Neuroscience, 10(5), 631-639.

Tager-Flusberg, H., \& Sullivan, K. (2000). A componential view of theory of mind: evidence from Williams syndrome. Cognition, 76(1), 59-90.

Tager-Flusberg, H., Sullivan, K., \& Boshart, J. (1997). Executive Functions and Performance on False Belief Tasks. Developmental Neuropsychology, 13, 487-413.

Tannock, R., Purvis, K. L., \& Schachar, R. J. (1993). Narrative abilities in children with attention deficit hyperactivity disorder and normal peers. Journal of Abnormal Child Psychology, 21(1), 103-117.

Vicari, S., Brizzolara, D., Carlesimo, G. A., Pezzini, G., \& Volterra, V. (1996). Memory abilities in children with Williams syndrome. Cortex, 32(3), 503-514.

Wechsler, D. (1991). Wechsler Intelligence Scale for Children: Manual (3rd ed.). San Antonio: Psychological Corporation.

Wechsler, D. (1997). WAIS-III: Manual. London: Psychological Corporation. 